\title{
REPRESENTACIÓN DE UNIDADES TERMINOLÓGICAS: EL MODELO DE TÉRMINO WÜSTERIANO
}

\author{
Andreína Adelstein
}

RESUMO: The purpose of this paper is to show the linguistic character of the term concept and its explanatory model in Wüster's work. The paper explains the steps in the denomination process and its representation model. The analysis of the variation registered in the texts relative to the concept of term itself and of its model, as well as the study of its theoretical and methodological consequences, is used to detemine the type of linguistic statute of the term in Wüster's opus.

PALAVRAS-CHAVE: termo, representação, unidade léxica, denominação, aplicações no Mercosul.

\section{INTRODUCCIÓN}

A menudo se emplea término para identificar la unidad de análisis de la terminología y de tratamiento terminológico. Sin embargo, existen diferencias respecto de qué tipo de entidad se trata. En efecto, en la bibliografía se ha utilizado término para referir realidades distintas, por ejemplo:

a) unidad lingüística de uso en dominios de especialidad o propia de los lenguajes de especialidad;

b) unidad léxica propia de los dominios de especialidad;

c) unidad semiótica de los dominios especializados (tanto unidades lingüísticas como no lingüísticas);

d) parte formal de una unidad semiótica de especialidad;

e) parte formal (o parte "significante") de una unidad lingüística de especialidad.

Dado que la obra de Wüster no sólo ha sido determinante para los seguidores de la TGT (Teoría General de la Terminología), sino también para las distintas orientaciones y perspectivas que actualmente existen en la terminología, este trabajo se propone analizar los textos de Wüster con el fin de determinar a qué llama término y qué modelo propone para dar cuenta de esta noción. ${ }^{1}$

No es nuestro objetivo aquí evaluar si el modelo de Wüster resulta adecuado para representar los elementos que intervienen en la unidad terminológica (UT), sino argumentar que para Wüster a) el término tiene un carácter exclusivamente lingüístico y que b) la representación que propone de él sigue un modelo lingüístico. El objetivo de este trabajo se enmarca, pues, en un objetivo más general, que aquí no cubriremos en su totalidad: revisar y evaluar los presupuestos teóricos de Wüster respecto del carácter lingüístico de la UT y de qué es, por tanto, lo estrictamente terminológico de estas unidades.

La obra de Wüster analizada por separado da lugar a diversas interpretaciones respecto del estatuto lingüístico o semiótico de las unidades de la terminología. En cambio, el análisis en su conjunto permite aclarar supuestas discrepancias o vacilaciones teóricas que presenta. Estas divergencias, al menos aparentes, podrían deberse a los

\footnotetext{
Andreína Adelstein é professora da Universidad Nacional de General Sarmiento (Buenos Aires) e Universitat Pompeu Fabra (Barcelona)

${ }^{1}$ Este trabajo forma parte de la revisión de modelos lingüísticos de representación de las unidades léxicas que estoy llevando a cabo en el marco de la tesis doctoral, con el fin de evaluar su adecuación explicativa y descriptiva respecto de la hipótesis de Cabré (1999) acerca de que las palabras y los términos son valores que puede adquirir una misma UL en distintos contextos de uso. 
siguientes motivos, no excluyentes entre sí: en primer lugar, a que la obra de 1979 es una recopilación de apuntes de clase de su discípulo Felber, publicada póstumamente. En segundo lugar, a que Wüster haya ido construyendo y reformulando su postura en las distintas conferencias o clases y a que, por lo tanto, haya ido distanciándose de los modelos lingüísticos con el fin de establecer, a modo de teoría, los principios que deben regir el trabajo terminológico. Este afán puede haber sido más marcado en los últimos textos y de allí la confusión que parecen plantear. En su obra de 1979, Wüster plantea cómo se ha de actuar sobre la UT para lograr en el dominio de las técnicas una comunicación especializada unívoca, eficaz y de carácter sobre todo internacional. Los textos que hemos escogido analizar son aquellos que, a nuestro modo de ver, son los más representativos para la noción de término. ${ }^{2}$

Nuestras hipótesis de partida del análisis que presentaremos son que:

a) término no designa la totalidad de la unidad terminológica (UT), sino sólo su parte formal;

b) término es sinónimo de denominación, y, respecto del modelo saussureano, de significante lingüístico. Es decir, un símbolo químico, por ejemplo, no es un término;

c) existen diferencias en sus obras respecto de la noción de término y del modelo que para él se propone; estas diferencias conllevan una variación en su postura respecto del objeto terminológico y del objetivo de la terminología;

d) el modelo de término propuesto en Wüster (1979) permite plantear un tratamiento monosémico y homonímico de las unidades terminológicas;

e) los modelos explicativos que presenta siguen los propuestos por la lingüística estructuralista, derivada de las hipótesis saussureanas.

Partimos, además, del supuesto de que una representación lingüística corresponde siempre a un modelo explicativo de cómo una teoría determinada considera cómo está constituido o qué información comporta un determinado fenómeno lingüístico. La representación, por tanto, no sólo es un modo de describir sino también de explicar. Para Wüster, cuyo artículo de 1959/60 se titula Das Worten der Welt, schaubildlich und terminologisch daergestellt, la ilustración (schaubildich) es un medio de explicación. El proceso de dar nombres o de dotar de palabras ${ }^{3}$ al mundo (Das Worten der Welt) lo explica (dargestellt) mediante ilustraciones (schaubildlich) desde la prespectiva de un terminólogo (terminologisch). En tanto estas ilustraciones son propuestas por Wüster como un modo de descripción y explicación, tales ilustraciones constituyen un modo de representar modelos explicativos del fenómeno.

En una primera parte presentaremos el proceso de denominación y su relación con la noción de término según las distintas obras de Wüster. En segundo lugar, trabajaremos el modelo de término, sus representaciones, y las consecuencias teóricas y aplicadas que de él se derivan. En una tercera parte, presentaremos las diversas clasificaciones de términos propuestas en Wüster (1979), la variación que presentan los términos y la expansión de la noción a otras unidades semióticas. Finalmente, daremos unas breves conclusiones a modo de síntesis.

\section{LA NOCIÓN DE TÉRMINO}

\section{El proceso de denominación}

El objetivo de Wüster (1959/60) es explicar en qué consiste el proceso de denominación del mundo, presentar las explicaciones que de él han dado distintos autores y proponer su propio modelo. ${ }^{4}$ Siguiendo a Weisgerber, llama al proceso de conceptualización de la realidad proceso de denominación del mundo objetivo, i.e "la resolución mental del mundo por el ser humano" (WÜSTER, 1959/60, p. 35). Este proceso, por el cual los seres humanos comprenden la realidad y pueden referirse a ella consta de tres pasos: la desintegración, la abstracción y la formación de nombres comunes.

El primer paso consiste en que a partir de los individuos (objetos, hechos) de la realidad circundante, el niño se forma un concepto individual (memoriza sus rasgos más sobresalientes de, por ejemplo, un perro determinado). Dado

\footnotetext{
${ }^{2}$ La traducción del catalán de las citas de Wüster (1959/69) y Wüster (1974) es nuestra.

${ }^{3}$ La palabra Worten es una verbalización de Wort = palabra, que a su vez está sustantivada. Se trata de un neologismo de Wüster, y significa "poner en palabras", "dotar de palabras". Agradecemos esta observación a Katja Ide y a Johannes Schnitzer.

4 "Los hechos y las relaciones complejas se pueden comprender más fácilmente con la ayuda de ilustraciones (diagramas, esquemas o gráficos). A continuación se pretende emplear este tipo de representaciones para describir las relaciones de diversas formas que se producen en el proceso de "denominación" del "mundo objetivo" (según Weisgerber) y en el discurso desde el punto de vista de un terminólogo. También se pretende reseñar las denominaciones más importantes que diferentes autores han asignado a estas relaciones.”(WÜSTER, 1959/60, p. 33)

Organon, Porto Alegre, n 26, 1998
} 
que todo objeto individual forma una unidad compleja, la formación de un concepto individual requiere de la operación de descomposición del individuo en partes (desintegración).

El segundo paso, la abstracción, consiste en que de los conceptos individuales (que en nuestro ejemplo corresponderían a los del perro $\mathrm{x}$, del perro $\mathrm{y}$, etc.) se abstraen las características comunes y se conforma el concepto genérico, en este caso el de perro. ${ }^{5}$

El tercer paso corresponde a la formación de nombres que implica necesariamente la identificación de los conceptos generales. Para la explicación de este paso, Wüster presenta previamente su concepción de proceso semiótico: cuando un hablante quiere referirse a un objeto individual que en la situación de comunicación se encuentra próximo a los participantes, basta con que lo señale. Pero si tal objeto no se halla presente, es preciso que apele al concepto individual correspondiente a tal objeto, que el interlocutor tiene. Para ello, debe recurrir a un elemento sustitutivo que lo represente. El signo es, para Wüster, un elemento sustitutivo que, en la comunicación o en la conciencia de los hablantes, permite identificar un individuo o un concepto. Por ejemplo, si un hablante quiere dirigir la atención de su interlocutor hacia el objeto individual "su coche", que no se halla presente, debe apelar al concepto individual correspondiente. Para ello, el hablante puede mostrar un objeto individual, por ejemplo "las llaves". Estas, por razones metonímicas, sustituyen al objeto que se quería identificar, apelando al concepto individual de coche. Ahora bien, en lugar de mostrar tal objeto sustitutivo, que no siempre estaría disponible, es más económico pronunciar una cadena fónica [mi kóše].

Pero la identificación de conceptos generales sólo es posible a través de otros conceptos generales que funcionen como signos. En nuestro ejemplo, para identificar el concepto genérico de coche sólo se pueden emplear signos fónicos ${ }^{6}$. Es decir, sólo pueden ser signos de conceptos generales otros conceptos generales, pues los objetos individuales sólo representan conceptos individuales:

Los conceptos generales únicamente se pueden identificar mediante signos, ya que los conceptos no se pueden ver. Cuando se muestra un representante individual de un concepto general, solo se transmite el concepto individual de este representante. Por este motivo la formación de conceptos generales permanentes o su apelación arbitraria a la mente propia y a la de los demás (en los monólogos y en los diálogos) tampoco es posible sin asignar a estos conceptos otros conceptos generales apropidos que hagan de signos. La asignación de signos - y especialmente la asignación de nombres es el tercer paso del proceso de denominación del mundo. Pero esto no significa que el tercer paso siga al segundo de manera claramente separada. Entre la formación de conceptos (segundo paso) y su denominación (tercer paso) existe un alto grado de interacción. El significado de un signo es aquello que designa. (WÜSTER, 1959/60, p. 39)

Wüster explica, pues, que la formación de nombres comunes consiste en el hecho de atribuir de manera permanente un concepto genérico fónico como signo de otro concepto genérico. Esto es, en nuestro ejemplo, otorgar a la cadena fónica /kóše / (que es un concepto genérico resultante de la abstracción de los diversos conceptos individuales alofónicos relativos a las diversas pronunciaciones orales) el estatuto de elemento sustitutivo del concepto general de coche. Vale decir, la formación de nombres y la identificación de conceptos generales son dos aspectos de un mismo paso: el tercero. Los nombres se forman con el fin de identificar un concepto genérico. El tercer paso correspondería, pues, a una función semiótica en la que un concepto genérico funciona como signo de otro concepto genérico.

Ahora bien, el llamar segundo y tercer paso a la formación de conceptos y a la formación de nombres, respectivamente, se debe a razones metodológicas o explicativas y no a cuestiones de orden lógico. Está claro que la formación de un concepto genérico sólo es posible si se lo puede identificar y, para ello, se requiere de una denominación. El segundo (formación de conceptos genéricos a partir de conceptos individuales) y el tercer paso (formación de nombres comunes) se requieren mutuamente; son procesos interdependientes:

La abstracción, pues, es el segundo paso del proceso de denominación. La denominación corresponde más a este segundo paso que al primero, porque la formación de los nombres comunes (tercer paso) únicamente es posible mediante la abstracción y, a la inversa, los nombres comunes hacen posible la abstracción. (WÜSTER, 1959/60, p. 37)

De esta explicación se desprenden, al menos, las siguientes conclusiones: a) el proceso de conceptualizar implica siempre un proceso semiótico; i.e. los conceptos genéricos no existen como tales independientemente de una forma que los identifique y a la vez los denomine, y b) los pasos del proceso de denominación siguen el modelo propuesto por Saussure. En efecto, si, por un lado, los conceptos genéricos -en definitiva lo que para Saussure constituyen el significado- son los que utilizamos para comunicar nuestro pensamiento $\mathrm{y}$, por otro, el nombre es el modo de

\footnotetext{
${ }^{5}$ Más adelante, Wüster señala que los conceptos genéricos también se pueden formar por determinación, es decir, a partir de un concepto genérico al cual se le agregan características. La abstracción implica un proceso ascendente o inductivo y la determinación, un proceso descendente o deductivo. La determinación le permite explicar la formación de conceptos cuyos individuos no existen en la realidad circundante.

${ }^{6}$ De aquí en adelante Wüster emplea signo exclusivamente para referirse a los signos de conceptos genéricos. Organon, Porto Alegre, nº 26, 1998 
designarlo, la explicación del proceso de denominación sigue la postura saussureana. No la contradice, en todo caso la amplía o la especifica más.

Para representar el proceso de denominación y sus pasos Wüster propone un modelo semiótico tetrádico. En la figura 1 reproducimos la presentada en Wüster (1969/69, p. 40). Mediante este esquema, que adaptamos ${ }^{7}$ en la fig. 2 , se representa lo siguiente:

a) los elementos que intervienen en los distintos pasos del proceso (individuos, conceptos individuales y conceptos genéricos) y las relaciones que se establecen entre ellos. Por ejemplo, de los individuos se abstrae y se forma el concepto individual ${ }^{8}$;

b) los pasos del proceso (véanse las flechas y el número que corresponde a cada paso) y las relaciones entre ellos: la abstracción y la denominación se requieren mutuamente (nótese que hemos utilizado una flecha doble para señalar la interdependencia entre el segundo y el tercer paso);

c) la unidad semiótica resultante, sus componentes y el tipo de relación que guardan entre sí: signo y significado son interdependientes.

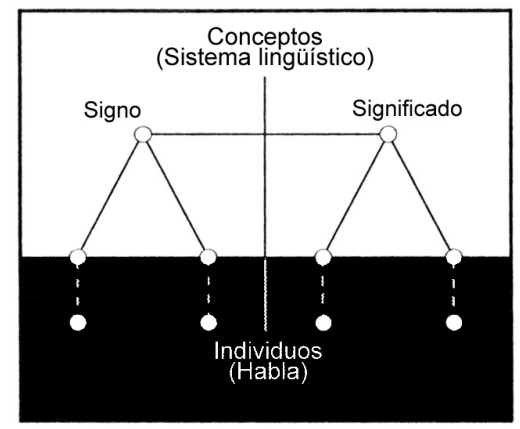

fig.1

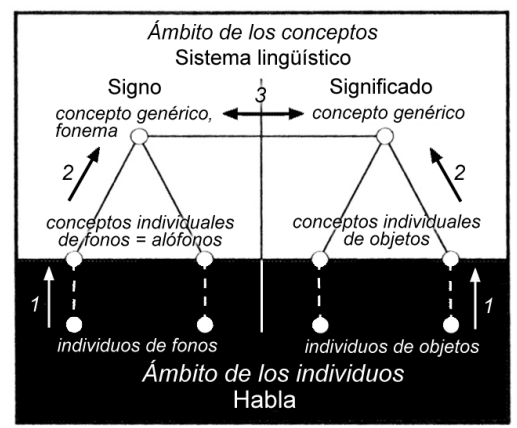

fig. 2

Este esquema, entonces, representa también las unidades lingüísticas. Es por ello que Wüster denomine a esta figura "modelo de palabra de cuatro campos". El signo es también un concepto, una entidad psíquica, producto de una abstracción (i.e. la forma fonológica y no la forma fónica, por ejemplo). El niño, al oír diversas pronunciaciones de una misma cadena fónica forma conceptos individuales (cadenas de alófonos) y a partir de ellos el concepto genérico de la cadena de fonemas. El sistema lingüístico se ubica en la interrelación de dos conceptos genéricos: el concepto genérico designado (significado) y el concepto genérico que lo identifica (el signo).

\section{Denominación, signo y término: la noción de término en 1959/60}

La unidad de la lengua es explicada como el "resultado" de los procesos de denominación y de formación de conceptos. El otorgarle una denominación a la relación entre signo y significado es una necesidad científica, producto de su interdependencia. Esta unidad es la unidad léxica:

Es indiscutible que los signos, particularmente los signos fonéticos, y su significado se condicionan recíprocamente. Una forma fonética sólo es un sonido físico sin significado, y un concepto no puede existir sin signo. De esta estrecha relación entre estos dos aspectos se desprende la necesidad científica de una expresión que designe este conjunto surgido de la integración. Se puede denominar unidad de designación o, restringida a las formas fonéticas, unidad de denominación; los anglosajones llaman a la unidad de denominación lexical unit (lexicon = vocabulario). (WÜSTER, 1959/60, p. 41-42)

La palabra término aparece por primera vez en este artículo en el contexto de cómo llamar a la unidad comprendida entre significado y signo; cuando señala los problemas que suscitan la terminología saussureana y la de otros autores. Sostiene que lingüistas y filósofos han recurrido a la figura de pars pro tot para denominar la unidad: Saussure, por ejemplo, emplea signo (lingüístico); otros, palabra. Deja claro que, para él, signo y palabra

\footnotetext{
${ }^{7}$ He utilizado la cursiva para mis observaciones.

${ }^{8}$ Justamente, para Wüster el proceso de denominación "se caracteriza por dos relaciones fundamentales: por un lado, las relaciones entre individuos y conceptos [primer y segundo paso] y, por otro, las relaciones entre signos y significados [tercer paso].” (WÜSTER, 1959/60, p. 33, los agregados en corchetes son nuestros). Estas relaciones son propias de toda lengua: "Las dos relaciones fundamentales, individuo-concepto y signo-significado, son ininterrumpidas y entonces efectivas en cualquier lengua." (WÜSTER, 1959/60, p. 40). 
corresponden al significante saussureano, ya que -señala- en lengua general signo y palabra sólo quieren decir la parte significante y no refieren a la unidad completa.

Plantea aquí una verdadera precisión terminológica y conceptual respecto de la unidad y de los elementos que la componen. Respecto del signo, propone, indirectamente, una tipología y una agrupación jerárquica: por designación, se refiere a signos gráficos o fónicos; por denominación, sólo a los signos fónicos. De allí que por unidad de denominación entienda lo que para Saussure es signo lingüístico. El término unidad de designación es un hiperónimo de aquel, ya que refiere tanto a las unidades formadas por un signo fónico como a las formadas por otro tipo de signo. Es en este pasaje que Wüster aclara que denominación y signo fonético son sinónimos de término:

Los lingüistas que hablan de signo o palabra, en lugar de unidad de denominación, son generalmente concientes de que con ello se apartan de la lengua general, que por estas palabras sólo entiende el signo relacionado con el concepto designado. Por esto se ven obligados a utilizar la palabra sustitutiva significante en lugar de la palabra de la lengua general signo, y la palabra sustitutiva cuerpo de la palabra, en lugar de palabra. Contra el uso de la palabra palabra en el sentido de "unidad de denominación" se puede formular aún una objeción más amplia: la parte del signo de una unidad de denominación a menudo no consta de una sola palabra (cuerpo de palabra), sino de un grupo de palabras más o menos fijas. El genérico de palabra (cuerpo de palabra) y de grupo de palabras, al cual se hace referencia aquí, se denomina término desde hace mucho tiempo. Desde hace algunas décadas se ha ido imponiendo cada vez más el sinónimo denominación. Esta expresión es semejante a la de designación, empleada ya desde hace tiempo, por la cual se entiende el genérico común de denominación y signo gráfico. (WÜSTER, 1959/69, p. 42)

En síntesis, término en Wüster (1959/60):

- es un concepto genérico, abstracción de conceptos individuales que corresponden a individuos fónicos;

- funciona como el signo de otro concepto genérico que, por tanto, es su significado;

- por ello, es un signo fónico y es sinónimo de denominación;

- puede ser una sola palabra (i.e. monoléxico) o un grupo de palabras (i.e. poliléxico). Dado que las denominaciones constituidas por más de una palabra son particularmente productivas en los dominios de especialidad, término en Wüster abarcaría tanto las formas de las unidades léxicas de lengua general como las de las especializadas;

- respecto de su representación, dado que la fig. 1 representa una unidad léxica simple (o los signos elementales) y en su significado fundamental, el término simple corresponde a la parte superior izquierda.

\section{La noción de término en 1974 y 1979}

Mientras que la primera mención a la noción de término en Wüster (1959/60) aparece en relación con las precisiones terminológicas respecto de cómo denominar la unidad léxica, la primera mención que hace en Wüster (1979) es en el contexto de la discusión acerca del estatuto epistemólogico de la terminología, en la que plantea las diferencias entre TGT y la Ciencia de la Lengua General:

La terminología considera que el ámbito de los conceptos y el de las denominaciones (=los términos) son independientes. Por esta razón los terminólogos hablan de conceptos, mientras que los lingüistas hablan de contenidos de palabras, refiriéndose a la lengua general. Para los terminólogos, una unidad terminológica consiste en una palabra a la cual se le asigna un concepto como su significado, mientras que para la mayoría de los lingüistas actuales, la palabra es una unidad inseparable compuesta de forma y contenido. Los terminólogos usan la expresión concepto, y no la de significado, por una razón básica: en su opinión, el significado de un término (el concepto) se agota en el significado denotativo, también llamado significado conceptual, y prescinde, en general, de las connotaciones. (WÜSTER, 1979, p. 21-22)

Esta cita refleja, aparentemente, un cambio de posición respecto de tres aspectos: a) la relación entre signo y concepto, b) el tipo de unidad de denominación en lengua general y en las terminologías, y c) el estatuto del término.

Por otra parte, esta cita puede interpretarse como una toma de posición respecto del modelo saussureano; da lugar a distintas interpretaciones respecto de qué entiende por UT y por lo tanto, por término:

1) La UT y la UL (unidad léxica de lengua general) son un mismo tipo de unidad lingüística, pero la terminología tiene una postura teórica diferente de la lingüística respecto de dicha unidad

2) La UT presenta ciertas diferencias respecto de la UL; Wüster acepta el modelo saussureano para la lengua general, pero no para la terminología.

3) La distinción establecida entre UL y UT es planteada por Wüster con fines metodológicos: separar lo que naturalmente es inseparable en la lengua y tratar de lograr unidades unívocas. 
Es decir, la interpretación 1) implica afirmar que Wüster considera que el modelo saussureano es un modelo lingüístico inadecuado para toda unidad léxica (incluyendo la UT), y por tanto propone otro. La interpretación 2), que UL y UT son unidades de distinto tipo; el modelo saussureano es adecuado sólo para la UL y propone uno para la UT. La 3), que si bien UT es un tipo de unidad léxica, el modelo saussureano es adecuado para la lingüística teórica (descriptiva y explicativa), pero no para la lingüística aplicada a las unidades de los lenguajes de especialidad. La interpretación 1) es muy radical y es obvio que hay que descartarla, sin embargo pareciera ser la que hacen, por momentos, algunos de sus seguidores; la 2) pareciera corresponder a la postura que Wüster adopta en varios pasajes de su obra de 1979; la 3) es la que adopta claramente en el artículo de 1959/60 y en algunos pasajes de 1974 y 1979.

Ahora bien, independientemente de estas diversas interpretaciones, en estas páginas término equivale a denominación, es decir a la parte significante o forma de la UT. Término ya no designa la parte formal de toda unidad léxica sino únicamente la de las unidades léxicas de especialidad. En Wüster (1979, p. 71) término es definido de la siguiente manera:

Nos dedicaremos a continuación al estudio de los símbolos lingüísticos de los conceptos, es decir, las denominaciones. Cuando el contexto de la denominación es tecnolectal, también se le llama término. Un término puede ser una palabra o un grupo de palabras.

En Wüster (1974, p.154) se da una definición semejante:

La palabra denominación, que he utilizado hace un momento, en terminología es la expresión habitualmente empleada para la designación lingüística, el nombre. La palabra término, que debe ser más familiar para la mayoría de lectores, se emplea generalmente para las denominaciones técnicas.

Es decir, término se utiliza de modo restringido: no sólo no designa la UT sino que se emplea para designar las denominaciones lingüísticas de conceptos, básicamente, de las técnicas. No es exactamente, pues, tampoco sinónimo de denominación, tal como lo emplea en 1959/60. Aquí, por otra parte, término y denominación refieren tanto a signos fónicos como a signos gráficos.

El término, además, es de categoría nominal, que puede corresponder a una unidad simple o a un sintagma lexicalizado. Al respecto, cabe señalar la observación que hace Wüster (1979, p. 33) acerca de los nombres propios y los nombres comunes:

3. Para denominar los objetos individuales se utilizan nombres propios, por ejemplo: el tornado Minna.

4 No obstante, la lengua se compone principalmente de palabras que no son nombres propios, sino denominaciones asignadas directamente a los conceptos.

5. En un momento determinado del discurso, la denominación del concepto facilita el nombrar un objeto individual, pero, en este caso, es necesario completar la denominación del concepto con una expresión deíctica que fije el objeto individual en el tiempo y/o en el espacio. Ejemplos: esta silla; la silla de nuestro presidente; la silla que compramos ayer.

Por otra parte, el término no siempre es exclusivamente una forma fonológica o gráfica ya que puede estar constituido por unidades dotadas de significado: "Un término (palabra o grupo de palabras) se compone de uno o varios elementos léxicos (morfemas)" (WÜSTER, 1979, p.71).

En síntesis, en Wüster $(1979,1974)$ término es: el concepto genérico que funciona como parte formal (gráfica o fónica) de una unidad lingüística de especialidad; es sinónimo denominación técnica y es de categoría nominal.

Ahora bien, si el concepto de una UT es designado o denominado por toda una unidad significativa de la lengua, cabe preguntarse qué ocurre con el significado léxico original. Ante esto propone su modelo de término.

\section{EL MODELO DE TÉRMINO}

\section{Las propuestas de 1979 y 1959/60}

En la siguiente cita, Wüster (1979, p.74) enuncia un modelo de término, que también propone en su artículo de 1959/60":

Cada término posee una forma externa (configuración, forma física). La mayoría de los términos tienen además una forma interna, es decir, un significado literal por oposición al significado final.

\footnotetext{
${ }^{9}$ Este modelo aparece también en el artículo de 1974, aunque no es su formulación completa.
} 
Este modelo se funda en el hecho de que los términos pueden estar constituidos por distintos elementos léxicos: pueden ser simples (i.e. no construidos), compuestos (i.e. construidos por composición o derivación), grupos de palabras (poliléxicos) o figurados.

Todo término tiene una forma externa (forma física, configuración fonológica o gráfica) y la mayoría (i.e. los términos que no son simples y a la vez patrimoniales) tiene una forma interna (que corresponde al significado de los elementos léxicos que lo componen: el significado de los morfemas, o de las palabras en el caso de los grupos de palabras, o el significado literal en el caso de las transferencias de sentido).

Según la estructura del término, la forma interna puede ser de dos tipos. Denomina forma interna sémica a la de los términos compuestos; a la forma interna de los términos transferidos la llama forma interna transferida.

Esta forma interna no ha de confundirse con el concepto (que en la cita es el "significado final") denominado por el término. Por ejemplo, la forma interna del término de lavadora sería el significado del verbo lavar más el significado agentivo del sufijo; en cambio el concepto designado es "máquina para lavar ropa". En el caso del término tansferido codo (en plomería), la forma interna es el significado "parte del brazo ..."; el concepto designado "tubo de x características". La noción de forma interna le permite a Wüster despejar al concepto de connotaciones y al término de polisemia, ya que sin negar su existencia ubica los significados connotados y los significados relacionados en la parte vehicular de la unidad.De manera esquemática planteamos el modelo de término, y su relación con el concepto designado, según 1979:

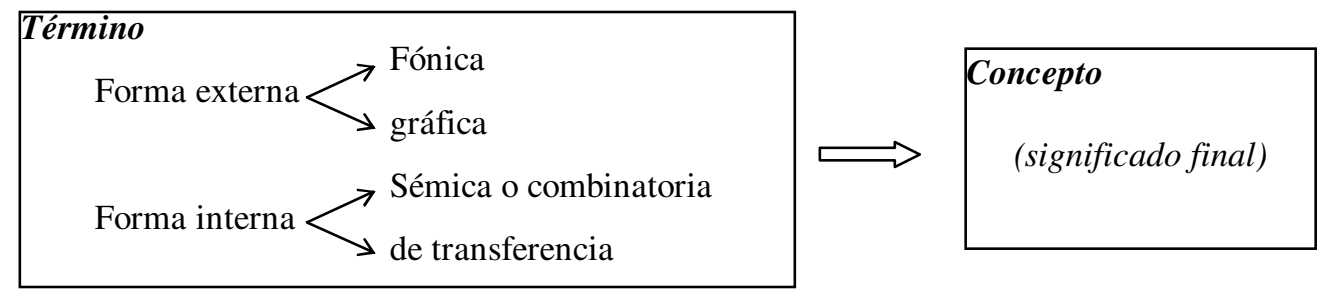

fig. 3

Respecto del modelo tetrádico de unidad, el modelo de término constituye una complejización de la parte superior izquierda.

Si bien este modelo de término se funda en el presentado en 1959/60, existen diferencias entre uno y otro. Wüster (1959/60), que también señala que el modelo tetrádico es la representación de unidades cuyos signos son simples, cuando analiza los signos complejos y los figurados plantea la noción de forma de sentido. Aclara que esta expresión la toma de Regula, pero que la noción la introdujo Marty con la designación de forma interna:

El modelo de palabra de cuatro campos sólo es válido de manera general para signos elementales y solo si se emplean con su significado fundamental. Los signos complejos y los signos figurados -el número de estos en la lengua es mucho más elevado- obligan a ampliar el diagrama. En el ámbito de los conceptos [i.e. en la parte superior] se ha interpuesto un campo nuevo entre el signo y el significado, que corresponde a la forma de sentido. La forma de sentido es el significado literal de los signos complejos o de los signos figurados; por ejemplo, el significado anatómico fundamental de las palabras cabeza y nariz, cuando no se habla de seres vivos sino de objetos sin vida. La forma de sentido es entonces significado y signo: es el significado básico del signo perceptible (por ejemplo de un signo fonético); es un concepto, pero en general no es ningún concepto fonético. Este concepto no fonético es, a su vez, el signo del significado resultante o final. (WÜSTER, 1959/60, p.44)

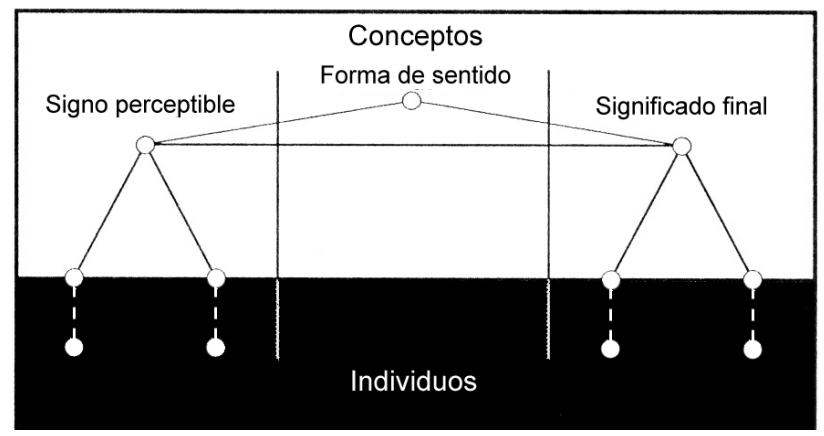

Organon, Porto Alegre, nº 26, 1998 
fig. 4

A diferencia de lo que propone en 1979, cuya lectura deja claro que tanto la forma externa como la interna pertenecen ambas al término, aquí la forma de sentido no corresponde estríctamente al término, sino que se "interpone" entre el término y el concepto; i.e. tiene un estatus intermedio entre signo y significado. No niega, pues, que el significado inicial esté, en cierta medida, "incluido"en el concepto designado que, por lo tanto, no es totalmente monosémico. Respecto de la representación de la unidad, en el caso de un término figurado, no corresponde a una complejización de la parte superior izquierda de la figura de cuatro campos, sino a otro tipo de representación, en la que intervienen otros elementos. La figura ya no sería un modelo de cuatro campos sino de seis:

En cuanto a los términos compuestos, señala en este artículo que también poseen forma de sentido: la forma de sentido compleja, que también se interpone entre el significado final y los elementos del "signo perceptible". Como ejemplo de representación para estas unidades propone la siguiente figura (WÜSTER, 1959/60, p. 46), que corresponde a una combinación disyuntiva, como indo-germánico, y que también sería un modelo de seis campos.

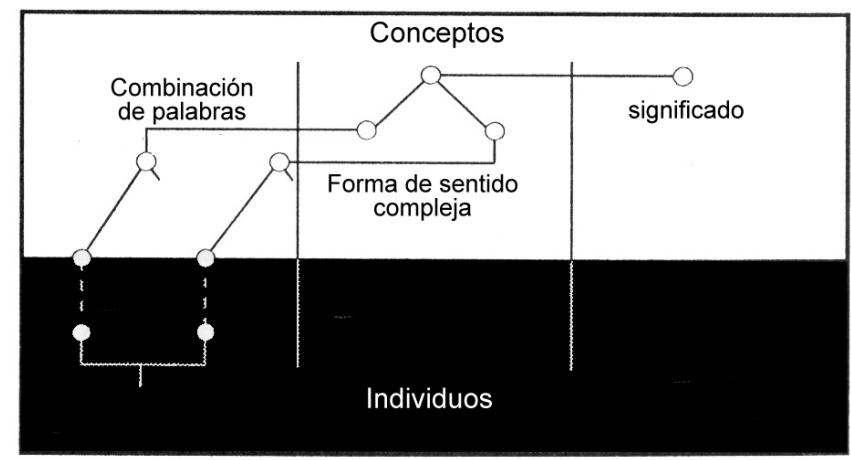

fig. 5

En este artículo, si bien habla de "signo perceptible", no propone la forma externa pues equivaldría al signo mismo; esto refuerza el hecho de que la forma interna no corresponden totalmente al término.

Es interesante señalar, además, que aquí el autor prefiere forma de sentido frente a forma interna. Aquella denominación -al igual que las que cita de Marty: forma semántica, forma conceptual- es más transparente respecto de su estatuto intermedio entre signo (forma) y significado (sentido). En cambio, la denominación forma interna refuerza la postura de 1979 de que, junto a su par forma externa, es exclusivamente un aspecto del signo o término.

En síntesis, los modelos de término y de UT, y sus correspondientes representaciones, varían en estas obras. La representación del modelo de término en Wüster $(1979,1974)$ sería una complejización de la parte izquierda de la figura tetrádica, pero aún cuando dicha complejización fuera diferente según el tipo de conformación del término, siempre es tetrádica. En cambio, en Wüster (1959/60), la representación de cuatro campos sólo corresponde a la UT simple; las unidades poliléxicas, complejas y las figuradas reciben, cada una, una diferente representación "de seis campos": las formas de sentido tienen un estatuto "más independiente", intermedio entre su capacidad designativa o denominativa y su capacidad semántica.

\section{La forma gráfica}

Como dijimos, Wüster (1959/69) no sólo no propone la forma externa, sino que, además, la forma de sentido está asociada exclusivamente a signos fónicos. En cambio, Wüster (1979) plantea que la forma externa puede ser fónica o gráfica (i.e. escrita). Esto puede resultar erróneo desde un punto de vista lingüístico, ya que la escritura es un sistema semiótico derivado de la lengua (o engendrado, en términos de Benveniste). Los sistemas de escritura son sistemas semióticos no lingüísticos, pero representan signos lingüísticos. ${ }^{10}$ En una palabra, en ningún modelo lingüístico se

10 La escritura alfabética, por ejemplo, es simplemente una representación de la forma fonológica. En términos de Barthes, un signo alfabético se compone de una expresión o significante (la letra) y un contenido o significado (el fonema).

Organon, Porto Alegre, n 26, 1998 
considera que la forma gráfica del ítem léxico sea uno de sus significantes; por ejemplo, en los modelos modulares no se propone un módulo gráfico, paralelo al fonológico.

Es claro que Wüster lo plantea con miras a la normalización terminológica y teniendo en cuenta la comunicación escrita:

La forma externa es, por una parte, la forma fónica (o pronunciación) y, por otra, la forma gráfica. Como comprobaremos, la forma gráfica tiene prioridad sobre la forma fónica en el caso de los términos internacionales. (WÜSTER, 1979, p. 74)

De todos modos aquella cita no resulta satisfactoria, si se considera que la UT es un tipo particular de unidad de la lengua natural. Wüster es consciente de ello en 1974:

A la concepción internacional de la lengua está relacionada otra particularidad fundamental de la terminología, que sonaría especialment herética: en terminología la forma escrita de las denominaciones tiene prioridad frente a la forma oral, es decir, frente a la pronunciación. (WǗSTER, 1974, p. 163, el grifo es nuestro)

Sin embargo, ¿cómo se ha de interpretar la forma externa? ¿Habría que suponer una forma externa más abstracta que, luego, se realiza de dos modos distintos: fónica o gráficamente? ¿Cómo se explica la relación de engendramiento entre la forma externa fonológica y la forma externa gráfica?

Creemos que esta noción de forma externa es propuesta también con fines metodológicos y se explica a partir de la noción de signo secundario. Sin embargo, la explicación de este tipo de signo es más clara en Wüster (1959/60, p. 47):

Supongamos que en el campo del medio [del modelo tetrádico] hubiese un signo que se pudiera realizar fácilmente, como se muestra en la figura 7. En un caso así el signo de este campo se consideraría primario (o directo) y el del campo izquierdo se consideraría secundario (o indirecto). En cuanto a las lenguas indogermánicas, el concepto de forma fonética es predominantemente el signo primario; este, por un lado, se puede realizar por sí mismo y, por otro lado, puede simbolizarse mediante formas escritas, como el signo secundario.

Es decir, la forma externa gráfica sólo puede darse gracias a la forma externa fonética: en las denominaciones lingüísticas la forma escrita siempre es una signo secundario. Según de qué lengua se trate, la UL puede no tener una forma gráfica; en terminología generalmente sí la tiene, y por ello se la incorpora al modelo de término.

\section{Consecuencias de los cambios en el modelo de término}

Las diferencias registradas en los textos analizados, permitirían afirmar que, aparentemente, entre el artículo del 1959/60 y la obra de 1979 habría un cambio en cuanto al modelo de término que, a nuestro modo de ver, implica un cambio de postura respecto de a) la relación término-concepto y b) la representación de la unidad de denominación. Se podría argumentar que este supuesto cambio de modelo, en realidad, es un cambio de objeto de análisis: en 1959/60 trataría con unidades de la lengua general, ya que prácticamente no establece diferencia alguna entre unidad léxica especializada y no especializada. ${ }^{11}$ En 1979 , trataría exclusivamente con unidades especializadas.

Sin embargo, creemos que sí hay un cambio y que éste consiste en que el objetivo en 1979 es proponer el marco teórico para el trabajo sobre las UT, y en 1959/60, el de describirlas. El cambio del modelo estaría determinado por una diferencia de enfoque (más teórico el de 1959/60, y más aplicado al trabajo terminológico el de 1979), que estaría justificada por los siguientes motivos: a) en 1979 Wüster trata por separado los conceptos (capítulos 2, 3 y 4) y las denominaciones (capítulo 5); b) es en este capítulo que explica la distinción entre forma externa y forma interna, i.e. ambas corresponden al término; c) la postura acerca de la diferencia entre terminología y lingüística, planteadas en el capítulo 0 .

De una u otra manera, es claro que el modelo de término de 1979 tiene consecuencias importantes tanto desde el punto de vista teórico como desde el aplicado. En efecto, la propuesta de que forma externa y forma interna corresponden ambas al término implica que:

a) el significado final no es estrictamente composicional;

b) el llamado significado literal se corresponde con la forma interna, es decir, no forma parte del concepto sino de la denominación;

c) los términos siempre designan un único concepto o un significado denotativo, dado que lo que habitualmente se llama significado connotado aquí es designado por una unidad de significación;

\footnotetext{
${ }^{11}$ A excepción de que aclara que expone la conceptualización desde el punto de vista de un terminólogo, y de que brevemente haga alusión a los dominios de especialidad cuando trata los conceptos innatos y los creados.
}

Organon, Porto Alegre, nº 26, 1998 
d) los términos transferidos (de un dominio a otro) no sólo corresponden a UT diferentes sino que son términos diferentes pues sólo coinciden en su forma externa;

e) se puede dar una misma representación para los distintos tipos de términos;

f) los términos formados a partir de reglas morfológicas o por resemantización (metafórica, metonímica, etc.) pueden recibir un tratamiento homogéneo;

g) se pueden establecer criterios para la normalización de denominaciones en un contexto internacional de comunicación especializada. Por ejemplo, la forma externa de formantes grecolatinos es bastante semejante en las distintas lenguas; en todo caso sí es uniforme su forma interna, i.e. el significado de estos formantes. ${ }^{12}$

\section{CLASIFICACIONES DE LOS TÉRMINOS}

A partir del modelo de término de 1979, se pueden establecer clasificaciones de términos diversas según: a) la forma externa; b) la forma interna; c) los elementos que constituyen el término (i.e. forma interna+forma externa). Más que por un afán descriptivo, dado que casi todas ellas siguen las reglas de formación de palabras, estas clasificaciones son presentadas en el capítulo 5 con el fin de establecer criterios de adecuación para la normalización. ${ }^{13}$

\section{Clasificación de términos según el origen de la forma externa}

Dado que para Wüster (1979) la forma externa de los elementos léxicos no está determinada por su significado sino por su origen, y que ésta puede ser gráfica o fónica, en el apartado 5.2.5.7. propone la siguiente clasificación, según si el origen es:

1. la propia lengua: palabras patrimoniales;

2. otra lengua préstamos: recientes o no asimilados, asimilados, efímeros;

3. otro dominio de especialidad: términos transferidos;

4. otras palabras: abreviaciones y contracciones:

4.1. abreviaciones, por ejemplo, sr.;

4.2. contracciones (también las denomina siglas o contracción deletreada), por ejemplo, IBM;

4.3. contracciones silábicas (o siglas enunciadas normalmente), por ejemplo, UNESCO;

4.4. contracciones directas (corresponden a las reducciones de palabras), por ejemplo, moto;

4.5. contracciones ampliadas (siglas con pronunciación silábica de letras)

4.6. abreviaturas de unidades matemáticas

Respecto de las abreviaciones y contracciones, plantea una clasificación que, a mi modo de ver, no sólo corresponde al origen de la forma externa, sino al procedimiento de formación:

apócopes (auto, por automóvil);

acrónimos (smog, por smoke y fog)

aféresis (bus, por omnibus)

frusta (tec, por detective)

Si se tiene en cuenta que para Wüster los términos son unidades léxicas, esta clasificación podría resultar extraña dado que incorpora formas que habitualmente no se consideran como tales: las abreviaciones y las abreviaturas matemáticas. Sin embargo, hay razones que la fundamenta ${ }^{14}$ :

a) la explicación de la forma interna gráfica como signo secundario;

b) el hecho de que estas unidades pueden ser base para la formación de palabras; y

c) el hecho de que flexionan (sr./sres.).

\footnotetext{
12 "En lo que hace a las denominaciones, su forma externa en última instancia está unificada en todo el mundo; si no es así, como mínimo es posible la unificación de la forma conceptual (=forma interna), es decir, la unificación del significado básico literal de las uniones de elementos y de las denominaciones figuradas." (WÜSTER, 1974, p. 162).

${ }^{13}$ De allí la cantidad de observaciones que hace sobre la pronunciación y la grafía de las abreviaturas y las contracciones.

${ }^{14}$ Por otra parte, Wüster, en el capítulo siguiente, admite que la inclusión de las contracciones puede resultar extraña:“Al tratar el tema de las contracciones, hemos dado al concepto de término una interpretación más amplia de lo habitual. Hemos tenido en cuenta el hecho de que el proceso de abreviación ofrece un nuevo recurso de formación de palabras [...]" (WÜSTER, 1979, p. 99)

Organon, Porto Alegre, nº 26, 1998
} 


\section{Clasificación de términos según la forma interna}

Wüster no plantea explícitamente una clasificación de este tipo; sin embargo, los términos se podrían clasificar según si su forma interna es sémica o de transferencia.

A su vez, respecto de los términos transferidos, podrían clasificarse según si su forma interna transferida es metafórica o metonímica: el tipo de asignación de una palabra como signo de otro concepto puede ser por una relación de contigüidad (metonimia) entre la forma interna y el concepto (significado final) o por semejanza (metáfora) entre la forma interna y el concepto designado por el término.

En Wüster (1979) con término transferido se refiere particularmente al término de un dominio de especialidad que se utiliza para denominar un concepto de otro dominio. De allí, por ejemplo, el término virus, que designa un concepto en medicina, al transferirse al dominio de la informática, el concepto médico corresponde a la forma interna del término virus que en informática designa otro concepto. Es decir, ambos términos son distintos: coinciden sólo en su forma externa, a pesar de que haya una relación semántica entre las unidades terminológicas.

\section{Clasificación según forma externa + forma interna}

En el apartado 5.1. Wüster (1979) propone una verdadera "lexicología" de la terminología, en tanto plantea los elementos constituyentes de la denominación y no de toda la UT. Los elementos que pueden constituir los términos son: elementos léxicos (raíces, afijos, elementos flexivos, i.e. morfemas de base, morfemas flexivos, morfemas léxicos), palabras (raíces, compuestas, derivadas; ie. palabras simples y complejas) y grupos de palabras (i.e sintagmas lexicalizados).

La lexicología es descriptiva y explicativa, Wüster, en cambio, intenta determinar qué tipos de procesos son "los más adecuados" para la formación de denominaciones de conceptos:

Ya he descrito hasta qué punto la investigación terminológica está marcada por la prioridad que tienen los conceptos, y la planificación y la orientación internacional de la lengua. Esta orientación influye también decisivamente en la simbolización de los conceptos, es decir, en la elección de las denominaciones concretas; esto es: la formación de palabras. (WÜSTER, 1974, p 171)

Wüster hace, entonces, una clasificación según qué elementos léxicos constituyen los términos. En la medida que estos elementos constitutivos son formas con significado, consideramos que esta clasificación es según la forma externa + forma interna:

1. Palabras raíz (Términos simples)

2. Términos compuestos:

2.1. por composición de morfemas: palabras derivadas, palabras compuestas

2.2. grupo de palabras

3. Términos transferidos

Si bien el modelo de término propuesto presupone que el concepto no es absolutamente composicional, Wüster plantea que la "combinación de morfemas como denominación de un concepto crea una definición abreviada del concepto" (1979:86), en la medida en que los significados de los elementos constitutivos corresponden a características del concepto designado. Es decir, anteojo bifocal designa el concepto genérico de un individuo que es un tipo de lente. Ahora bien, los constituyentes de aquel término son términos que designan también conceptos genéricos. Su combinación expresa que el concepto genérico correspondiente, es un concepto formado por determinación. Es por ello que: a) a la combinación de estos elementos a veces la llame forma conceptual (o interna sémica) y b) que sostenga que constituye una definición abreviada del concepto, lo cual no es equivalente a decir que sea el concepto mismo, dado que éste posee otras características. En este sentido, a los términos compuestos los llama formas abreviadas, que no hay que confundir con las abreviaciones.

Es decir, la forma interna sémica, entonces, no sólo constituye un significado de base sino que manifiesta el proceso de formación del concepto designado. 
Dado el objetivo fundamental de la terminología, Wüster plantea dos aspectos relacionados de los términos compuestos a tener en cuenta a la hora de crear términos o de normalizarlos: a) el grado de transparencia (cuán explícitamente el término manifiesta la relación entre los conceptos o características del concepto final), y b) el grado de abreviación (qué características expresa).Obviamente, cuanto más abreviado es el término, menos transparente es.

\section{Variación de los términos}

La variación en los términos se plantea de manera implícita en la obra de Wüster, y resulta problemática debido, por un lado, al ideal de UT monosémica y mononímica; por otro, a ciertas observaciones que hace en la clasificación de los términos. Esta variación aparece en las distinciones entre:

a) forma gráfica vs. fónica;

b) abreviación vs. término no abreviado;

c) contracción (sigla), contracción silábica (sigla enunciada normalmente) vs. formas sintagmáticas;

d) contracción ampliada vs. sigla;

e) contracción directa vs. forma no contraída;

f) palabra derivada, grupo de palabra y compuesto (formas abreviadas) que pueden designar el mismo concepto.

¿Cómo se resuelve esta variación en el modelo presentado? En algunos casos la variación no afecta a la UT sino únicamente a la estructura del término; otros casos sí constituyen variación denominativa:

a) Dado que la forma externa de un término puede ser a la vez gráfica y fónica, éstas constituyen variantes de una parte del mismo término y no dos términos distintos. Por otra lado, puesto que la forma gráfica nunca es independiente sino que es un signo secundario, cuando se lee o se escribe, remite a la forma fonológica: esta variación es interna al término y no afecta la UT. Desde este punto de vista, la forma fonológica /bírus/ y la forma escrita virus corresponden al mismo término y, junto con el concepto designado, constituyen una misma UT en un dominio de especialidad.

b) La abreviación (por ejemplo, sr.), según vimos, es una forma gráfica abreviada de la forma gráfica de señor. En la medida en que se pronuncia igual, no constituye otro término (en todo caso sería un signo secundario de otro signo secundario o forma externa gráfica).

c) Las siglas constituyen un caso diferente dado que no se trata únicamente de formas escritas; también se pronuncian distinto de los sintagmas que les dieron origen. Las siglas serían variantes denominativas respecto de tales sintagmas, aun cuando éstos constituyan su forma interna.

d) Las contracciones ampliadas son una variante fónica de una forma gráfica; vale decir serían dos términos ya que coinciden en su forma interna gráfica, pero difieren en la fónica.

e) Las formas contraídas afectan tanto la forma externa fónica como la gráfica de la palabra no contraída, por lo cual constituyen otro término diverso. Son casos de variación denominativa. ${ }^{15}$

f) También estas denominaciones constituyen variantes denominativas cuando designan el mismo concepto.

\section{EXPANSIÓN DE LA NOCIÓN DE TÉRMINO}

En los caps. 6/7 y en el 6 Wüster (1979) integra el término en el conjunto de los sistemas semióticos. ${ }^{16}$ Explicita que el modelo tetrádico de unidad de denominación puede aplicarse a todo elemento semiótico. A partir de ello, propone diversas clasificaciones de signos (ya no como sinónimo de término, sino en sentido general, i.e como la parte vehicular de cualquier unidad semiótica):

En este apartado ampliaremos nuestro campo de estudio a todos los tipos de signos. La noción de signo abarca el concepto de término. (WÜSTER, 1979, p. 99)

\footnotetext{
${ }^{15}$ Cuando trata la localización de la contracción, pareciera que todos estos casos los considera términos diferentes y no un mismo término: "Una de las vías para detectar las contracciones (y también las abreviaciones) por su forma consiste en determinar de qué parte del término completo proceden las letras que forman la abreviación" (WÜSTER, 1979, p. 83, el subrayado es nuestro).

${ }^{16}$ Esta propuesta es más reciente, no aparece en los artículos de 1959/60 y 1974. Organon, Porto Alegre, n 26, 1998
} 
Esta propuesta se funda en dos motivos: a) la lengua es el modelo de todo sistema semiótico ${ }^{17}$; b) en los lenguajes de especialidad, los términos, tanto en su forma externa escrita como gráfica, se combinan con otros tipos de signos.

Por "expansión del concepto de término" entendemos, pues, que no plantea que los signos no lingüísticos de especialidad sean, o haya que denominarlos, términos, sino que pueden ser explicados con un modelo semejante, y que merecen ser estudiados. Creemos que propone una "semiótica de los signos de especialidad" como una disciplina que abarca la terminología. Establecería, entonces, una relación análoga a la planteada por Saussure entre semiología y lingüística.

Es esta propuesta, tal vez no explicitada suficientemente, la que han considerado algunos de sus seguidores para considerar que son términos tanto los signos lingüísticos como los no lingüísticos.

En el capítulo 6/7 Wüster (1979) distingue signos naturales de signos convencionales, entre los que se encuentran los términos. Plantea luego una serie de clasificaciones de los tipos de signos convencionales (capítulo 6) y una clasificación de los signos gráficos (capítulo 7). Estas clasificaciones se vinculan, aunque no explícitamente, con propuestas hechas por semiólogos como Peirce y Prieto. No entraremos en ellas, simplemente señalaremos qué tipo de signo es el término según estas clasificaciones. Un término, por ejemplo pararrayos, considerado en su forma externa fónica es:

- por su forma (i.e según el signo en sí mismo),

- según el órgano sensorial implicado: auditivo

- según su estructura (dado que es un término compuesto): complejo

- por el significado que designa (i.e. el concepto),

- según el rendimiento lingüístico: representativo,

- según la relación con la lengua: semántico,

- según el campo de aplicación: técnico

- por su adscripción al significado:

- según la transparencia ${ }^{18}$ : no imitativo

- según la inmediatez del significado: primario

\section{CONCLUSIONES}

El estatuto epistemológico de la terminología ha sido siempre determinado en relación con el de la lingüística. En efecto, la delimitación entre lingüística y terminología y el intento por establecer diferencias entre sus respectivos objetos de estudio han sido un tema de preocupación en Wüster y sus seguidores. En la actualidad, en cambio, la TCT (Teoría Comunicativa de la Terminología) de Cabré (1999) es una propuesta de base linguística que, sin negar otros aspectos cognitivos y comunicativos de la UT, se funda en su carácter de unidad de lengua natural. Creemos que el afán, de algunos autores posteriores a Wüster, por otorgarle un estatuto científico propio a la terminología ha hecho que a veces se descuidara este aspecto. Por ello, pensamos que es importante revisar los fundamentos lingüísticos de la obra wüsteriana, algunas veces negligidos. Hemos intentado demostrar aquí, respecto de una noción clave como la de término, que en Wüster no sólo no se niega su carácter lingüístico sino que es justamente este carácter el que sostiene sus propuestas para el trabajo terminológico. Por otra parte, nos parece que el análisis de las representaciones que Wüster plantea resulta útil a la hora de evaluar y proponer modelos de representación lingüística para las unidades de la terminología.

Creemos haber demostrado que en Wüster unidad de denominación (para nosotros, UT) y término designan entidades diferentes. En sus obras, Wüster recurre a un modelo tetrádico para explicar la conformación de la UT; este modelo explicita que, para Wüster, el proceso de conceptualizar la realidad es interdependiente del proceso de formación de las unidades del lenguaje. Wüster (1959/60) plantea su modelo de UT como un desarrollo natural del modelo binario, a partir de la explicación más exhaustiva de cómo se forman los conceptos, y también como una superación del modelo triádico. En efecto, explica aquello que en Saussure resulta vago: los conceptos son "ideas", los

17 "En sentido amplio, un sistema cualquiera de signos constituye un lenguaje, una generalización del lenguaje verbal” (WÜSTER, 1979, p.100).

${ }^{18}$ En este apartado Wüster utiliza "transparencia" para referirse básicamente al grado de iconicidad de signos gráficos que representan objetos. En este sentido, un término es no imitativo. Sin embargo, dado que la transparencia definida más arriba se refiere al grado en que un término compuesto refleja la estructura del concepto, podría decirse que es medianamente transparente (es decir en cierto grado "imitativo").

Organon, Porto Alegre, nº 26, 1998 
significantes "huellas psíquicas sonoras". A su vez, se podría afirmar que este modelo se corresponde con el de Hjelmslev: respecto del contenido, la sustancia del contenido, corresponde en Wüster a los conceptos individuales de objetos, la forma del contenido, al concepto genérico correspondiente (significado). Respecto de la expresión, la sustancia corresponde a los alófonos; la forma de la expresión, a los fonemas. Es por ello que podemos afirmar que Wüster sigue modelos lingüísticos de corte tradicional o estructuralistas para explicar la UT.

En cuanto al término, hemos visto que en todas sus obras es la parte formal de la unidad, y es sinónimo de denominación; es, a su vez, un concepto genérico que funciona como signo de otro concepto genérico. Hemos señalado, también, que la noción de término presenta ciertas variaciones: en 1959/69 término y denominación designan sólo signos fónicos de cualquier tipo de unidad léxica. En cambio, en 1974 y 1979, por término y denominación se refiere tanto a signos fónicos como gráficos de las unidades de denominación técnicas. Esta variación se manifiesta también en su modelo de término: en 1959/69, la forma interna (o de sentido) tiene un estatuto intermedio entre signo y significado, mientras que luego es simplemente una aspecto del signo. Pero ambas versiones del modelo, así como su expansión a otras unidades de significación especializada siguen los modelos lingüísticos estructuralistas, a partir de Saussure.

Las diferencias en los modelos de UT y de término, además, tienen consecuencias en el plano metodológico o aplicado de la terminología. Creemos que el análisis presentado sobre la variación en los textos wüsterianos permite justificar, desde los modelos y sus representaciones, lo que autores como Cabré (1999) señalan como insuficiencias metodológicas de la TGT.

La noción de forma interna, en tanto constitutiva del término (y no como aspecto del contenido semántico), y la incorporación de la forma externa gráfica, con el mismo estatus que la fónica, avalan las pautas del trabajo terminológico planteados en 1979. En efecto, los criterios metodológicos y terminográficos de esta obra corresponden a un tipo de trabajo terminológico en un contexto internacional, de normalización, que tiene en cuenta la comunicación especializada escrita. En cambio, en Wüster (1959/60) se reconoce que las unidades complejas lo son también en cuanto a su parte conceptual. La representación en cuatro campos o en seis campos tiene repercusiones en la práctica: el modelo de cuatro campos permite aislar el concepto y trabajar sólo con la parte designativa; el modelo de seis campos no permitiría aislar de manera tan obvia el concepto, y obligaría a un tratamiento más integrador.

Es así que el modelo para la UT de 1959/60 resulte más adecuado para una terminografía descriptiva. En cambio, el de 1979 permitiría sólo cierto tipo de aplicaciones, generalmente prescriptivas y en un marco de comunicación tal como señalamos más arriba.

En una palabra, el giro que toman los modelos de UT y de término permiten establecer criterios metodológicos para intervenir en la interdependencia del signo (o término) y el significado (o concepto). De allí que, entre otras cosas, los modelos de 1979:

a) no permiten un tratamiento polisémico, en la medida que, por ejemplo, el o los sentidos literales de un término transferido no se consideran constitutivos del contenido semántico de la unidad; inducen, pues, a un tratamiento homonímico de los términos;

b) al separar el significado final de los elementos formales y semánticos constituyentes, permiten tratar el concepto de manera independiente de la lengua a la que está relacionado; i.e. permiten un tratamiento onomasiológico pero no semasiológico de las UT;

c) inducen a un tratamiento idéntico (por ejemplo, en cuanto al tipo de información que debe representar un artículo terminográfico) de términos creados por distintos procesos de formación.

\section{BIBLIOGRAFÍA}

CABRÉ, M.Teresa La terminología: representación y comunicación. Barcelona, Institut Universitari de Lingüística Aplicada de la Universitat Pompeu Fabra, 1999.

WÜSTER, Eugen. La denominació del món representada gràficament i terminològicament. In: M.T. Cabré (dir). Terminologia. Selecció de textos d'E. Wüster. Barcelona, Servei de Llengua Catalana de la Universitat de Barcelona, 1996.

WÜSTER, Eugen. La teoria general de la terminologia: una zona fronterera entre la lingüística, la lògica, l'ontologia, la informàtica i les ciències especialitzades. In: M.T. Cabré (dir). Terminologia. Selecció de textos d'E. Wüster. 
Barcelona, Servei de Llengua Catalana de la Universitat de Barcelona, 1996.

WÜSTER, Eugen. Introducción a la teoría general de la terminología y a la lexicografía terminológica. Barcelona, Institut Universitari de Lingüística Aplicada de la Universitat Pompeu Fabra, 1998. 